\title{
Муравьёв К.А. \\ Технология электрошлаковой наплавки стальной заготовки в кристаллизаторе прямоугольного сечения
}

Филиал Тюменского индустриального университета в г. Сургуте Сургутский институт нефти и газа (Россия, Сургут)

doi: $10.18411 / \mathrm{sr}-10-02-2018-09$

idsp: 000001:sr-10-02-2018-09

Актуальность темы. Электрошлаковая наплавка плоских поверхностей заняла прочные позиции в сварочном производстве, особенно в ремонтно-восстановительных работах в тяжёлом машиностроении и в производстве двухслойных сталей [3]. Характерной особенностью такой наплавки является значительная толщина наплавки и необходимость ограничения глубины провара наплавляемой поверхности, а также существенные габариты наплавляемой поверхности. Абсолютные значения величины износа могут достигать 100-150мм, а количество наплавляемого металла на одну деталь нескольких тонн. Примером может быть восстановление изношенных рабочих поверхностей станин кузнечных молотов и молотовых баб на Ижевском металлургическом заводе [3].

Постановка проблемы и анализ литературы. Совершенствование технологии электрошлаковой наплавки привело к появлению электрошлаковых технологий с использованием жидкого присадочного металла и применению токоподводящего кристаллизатора для поддержания необходимого температурного режима шлаковой ванны. Это позволило существенно повысить производительность наплавки и ограничить проплавление основного металла, благодаря разрыву жёсткой связи между производительностью процесса и мощностью на шлаковой ванне. Такая технология нашла довольно широкое применение при производстве валков прокатных станов. Вместе с тем, попытка использования этой технологии применительно к плоским поверхностям [1] пока не нашла должного распространения, в значительной степени, в связи с недостаточной изученностью процесса теплораспределения в шлаковой ванне прямоугольного сечения. Между тем распределение тепла в шлаковой ванне и топография проплавления наплавляемой заготовки в кристаллизаторе прямоугольной формы носят существенно более сложный характер, чем в цилиндрическом кристаллизаторе.

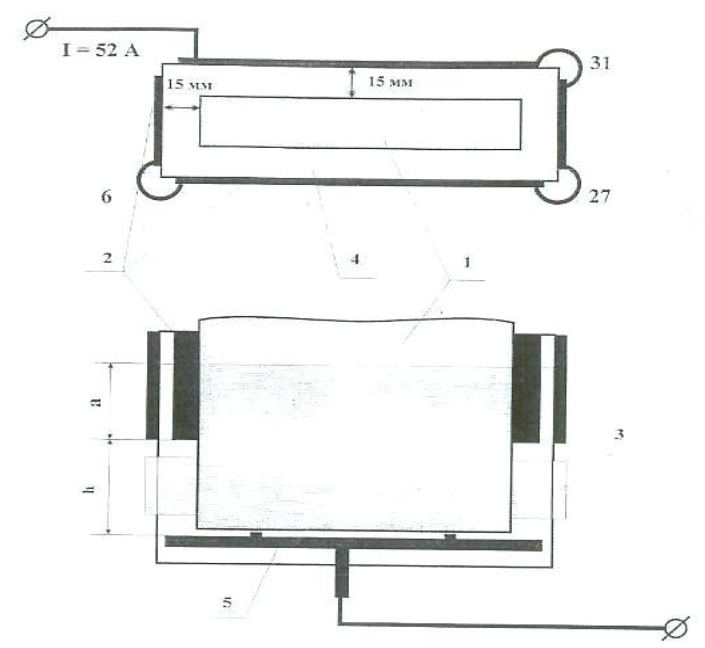

Рис.1. Схема расположения заготовки и подключения кристаллизатора с одним разрывом электрической цепи токоподводящих элементов. 1-Заготовка; 2- токоподводящая секиия (электроды); 3- промежуточная секияя; 4- раствор, моделируюший шлаковый расплав; 5- поддон; а- заглубление электродов в раствор (40мм); h- расстояние от поддона до токоподводящей секции 
В связи с трудоёмкостью и ограниченной возможностью снятия необходимой информации при выполнении натурных экспериментов, исследование процесса распределения тепла и проплавления заготовки при электрошлаковой наплавке в токоподводящем кристаллизаторе прямоугольного сечения проводили с использованием физической модели, описанной ранее в работах [4, 7]. Учитывая, что при реальной наплавке основной и присадочный материалы часто имеют близкие, а иногда и одинаковые физические свойства, в качестве материала для наплавляемой заготовки, а также жидкого присадочного металла использовали один и тот же материал: сплав Вуда, который хорошо зарекомендовал себя в холодных физических моделях электрошлаковых процессов [2]. В качестве среды моделирующей расплав шлака использовали концентрированный раствор хлористого кальция.

Учитывая, что распределение в шлаковой ванне тока, проходящего к наплавляемой поверхности неравномерное, фундаментальным фактором, определяющим характер проплавления заготовки, является величина и местоположение в шлаковой ванне участка с максимальным током.

В работе [4] было показано, что максимальный ток при электрошлаковом нагреве заготовки в токоподводящем кристаллизаторе проходит у нижнего торца электродов токоподводящей секции. Было высказано закономерное предположение о том, что именно на этом уровне должно наблюдаться максимальное проплавление заготовки при её нагреве в шлаковой ванне. Ранее [8] считалось, что такое проплавление (до подачи присадочного металла в зазор между заготовкой и токоподводящим кристаллизатором) находится у поверхности шлаковой ванны. После формирования зеркала металлической ванны участок максимального проплавления заготовки располагается непосредственно над поверхностью раздела металлической и шлаковой ванн $[5,8]$, т.е. существенно ниже поверхности шлаковой ванны и уровня нижнего торца электродов токоподводящей секции кристаллизатора. Такая “миграция” участка максимального проплавления связана с перераспределением тока на различных стадиях процесса электрошлаковой наплавки.

Цель настоящей работы состоит в определении влияния схемы подключения токоподводящего кристаллизатора прямоугольного сечения на характер проплавления заготовки по её периметру, определении участков максимального проплавления, как на стадии её нагрева в шлаковой ванне, так и в процессе наплавки жидким присадочным металлом.

Результаты исследований и их обсуждение. Для исследования выбрали схемы подключения токоподводящей секции, преимущественно с одним и с двумя разрывами в цепи электродов. На рис.1 представлены схема расположения заготовки в токоподводящем кристаллизаторе и одна из схем его подключения. Как и ожидалось, при схеме подключения с одним разрывом в цепи электродов токоподводящей секции наибольшее проплавление наблюдалось на участке соответствующем месту подсоединения токоподводящего кабеля и составило 5 мм. В целом же по периметру плоской заготовки величина проплавления колебалась в пределах от 2 до 5 мм, возрастая на углах заготовки. При наличии двух симметрично расположенных разрывов (см. рис. 2a) проплавление заготовки по периметру стало более равномерным и в условиях эксперимента составило от 4 до 5 мм (рис. 2б). Результаты экспериментов полностью совпадают с данными по распределению тока в таком кристаллизаторе, полученными в работе [4]. Максимальное проплавление заготовки при её нагреве в шлаковой ванне наблюдалось у нижнего торца электродов токоподводящей секции. 


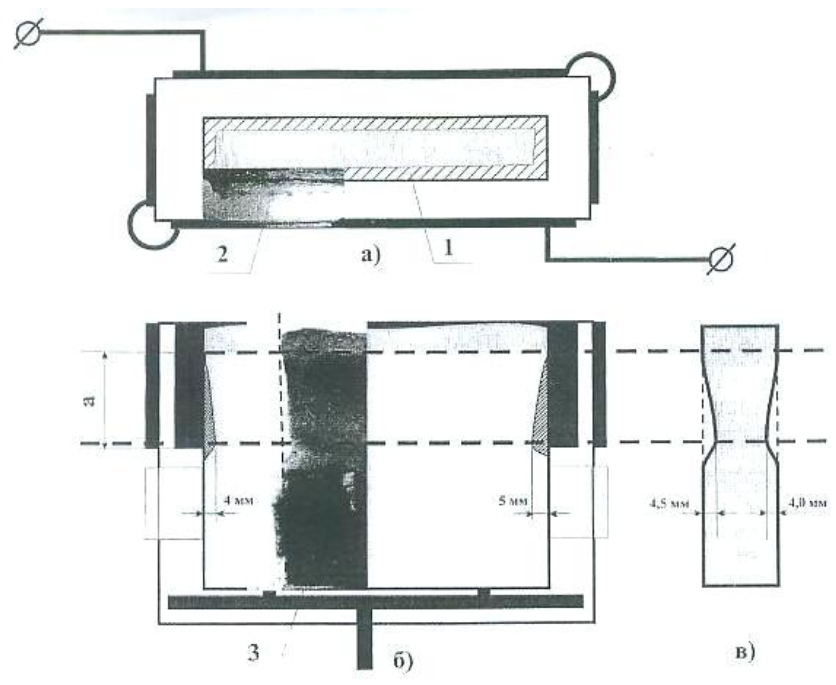

Рис. 2. Форма проплавления заготовки в плоском токоподводящем кристаллизаторе. а) вид с верху - максимальная глубина проплавления (1) по периметру заготовки и фотофрагмент поверхности в начальной стадии проплавления (2); б), в) проплавление заготовки по отношению к уровню

Как показали эксперименты, на стадии наплавки расположение участка максимального проплавления зависит от соотношения толщины наплавляемого слоя и расстояния от токоподводящей секции до уровня металлической ванны. В случае, когда толщина наплавляемого слоя составляла 15 мм, а расстояние от токоподводящей секции кристаллизатора до уровня залитого металла - 25 мм, проплавление наблюдалось непосредственно над уровнем залитого металла, как это и отмечалось в работах $[5,8]$. Однако, при уменьшении толщины наплавляемого слоя (в условиях эксперимента изменяли размеры наплавляемой заготовки) до 7 мм, отмечено перемещение участка проплавления вверх к токоподводящей секции. Максимальное проплавление отмечено на уровне промежуточной секции (рис.3a).
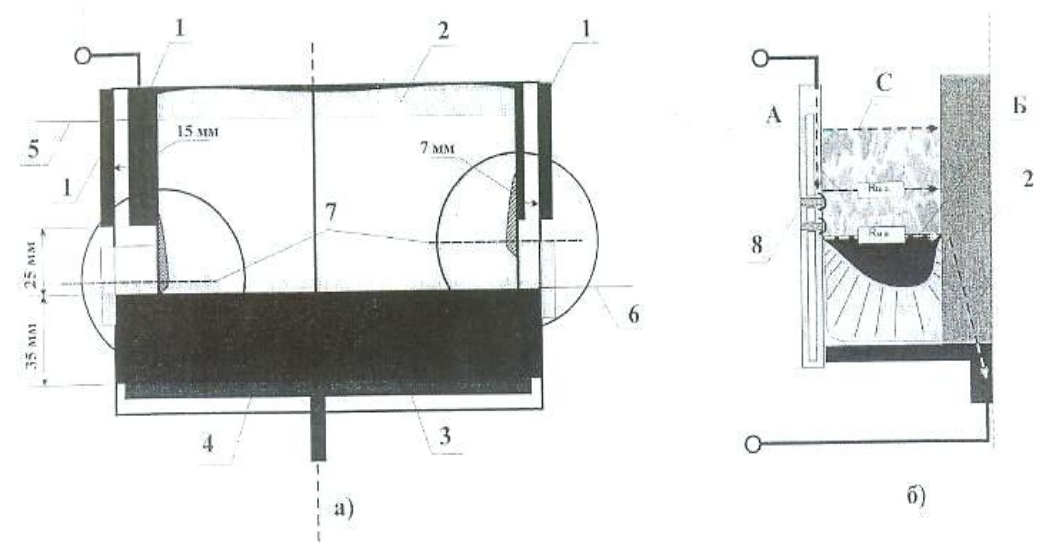

Рис. 3. Схемы проплавления и распределения тока в токоподводящем кристаллизаторе прямоугольного сечения при наплавке: а) расположение участка проплавления заготовки в зависимости от соотношения величин наплавляемого слоя и расстояния от токоподводящей секции до уровня металлической ванны;; б) распределение тока:

1 - электроды токоподводящей секиии кристаллизатора; 2 - наплавляемая заготовка; 3 - поддон; 4 наплавленный слой; 5 - уровень моделирующего шлак раствора; 6-уровень металлической ванны; 7 участки проплавления; 8 - изоляторы между секциями кристаллизатора.

Расположение инженерного торца электродов токоподводящих секций и фотофрагмент боков поверхности после проплавления (3).

Моделирование стадии наплавки проводили на новой заготовке. После подключения токоподводящей секции и предварительного подогрева заготовки производили заливку сплава в зазор кристаллизатора на поддон. Поддон с заготовкой не 
перемещали, заливку сплава проводили при температуре около 1000С одной порцией, в результате чего образовался слой высотой 35 мм, верхняя часть которого создавала электрический контакт между медной промежуточной секцией и наплавляемой заготовкой. Уровень моделирующего шлаковый расплав электролита поддерживали постоянным, для чего в верхней части кристаллизатора было выполнено сливное отверстие.

Изменение расположения участка проплавления связано с перераспределением тока на участке между электродами токоподводящей секции и поддоном, на котором установлена наплавляемая заготовка. На рис. $3 б$ указаны две цепи (А и Б), по которым возможно протекание тока от токоподводящей секции кристаллизатора к наплавляемой заготовке. На стадии нагрева заготовки в шлаковой ванне, когда подачи жидкого металла ещё нет, максимальная плотность тока приходится на цепь А (см. рисунок) и естественно проплавление заготовки начинается у нижнего торца электродов токоподводящей секции. Электрическое сопротивление этой цепи состоит из сопротивления медного токоподводящего электрода, контактного сопротивления электрод - шлаковая ванна, сопротивления шлака в зазоре между кристаллизатором и наплавляемой заготовкой (Rш.з.), контактного сопротивления шлаковая ванна - наплавляемая заготовка и сопротивления самой наплавляемой заготовки на участке до поддона:

$$
\mathrm{R}_{\mathrm{A}}=\mathrm{R}_{\text {си эл. }}+\mathrm{R}_{\mathrm{K} \mathrm{э-шл.}}+\mathrm{R}_{\text {ш.з. }}+\mathrm{R}_{\text {к шл.- н.заг. }}+\mathrm{R}_{\text {н.заг. }}
$$

Почему максимальная плотность тока приходится на цепь $\mathrm{A}$, (как это установлено в [3]), а не на цепь C, сказалось бы аналогичным сопротивлением. Здесь можно высказать следующие соображения. Во-первых, основной составляющей в сопротивлении этих цепей является сопротивление шлака в зазоре - Rш.з., которое в свою очередь существенно зависит от температуры. Поверхностные слои шлаковой ванны охлаждаются более интенсивно, а, следовательно, и электрическое сопротивление этих слоев будет выше. Во-вторых, цепи А и С отличаются тем, что в первом случае ток, на участке погружения электродов токоподводящей секции в шлаковую ванну, проходит по медному электроду, а во втором - по стальной наплавляемой заготовке. Электропроводность меди выше, следовательно, большая часть тока будет проходить по этой цепи. На практике, при наплавке стальных заготовок используют кристаллизаторы с медной токоподводящей секцией, поэтому проплавление на стадии нагрева заготовки всегда будет находиться на уровне нижнего торца электродов токоподводящей секции. Однако возможно, что при наплавке медных заготовок или в общем случае, когда электропроводность материала наплавляемой заготовки будет выше, чем электропроводность материала электродов токоподводящей секции, проплавление будет располагаться у поверхности шлаковой ванны. Этот вопрос требует дополнительной проверки.

После подачи жидкого металла в зазор и формирования металлической ванны, возникает новая электрическая цепь Б, сопротивление которой может быть представлено следующим образом:

$$
\begin{gathered}
\mathrm{R}_{\mathrm{b}}=\mathrm{R}_{\text {си эл. }}+\mathrm{R}_{\text {к э-шл. }}+\mathrm{R}_{\text {шл. из1. }}+\mathrm{R}_{\text {к шл-пр.с. }}+\mathrm{R}_{\text {пр.с. }}+\mathrm{R}_{\text {к пр.с.-шл. }}+\mathrm{R}_{\text {шл. из2. }}+\mathrm{R}_{\mathrm{K} \mathrm{шл-}} \\
\text { ф.с. }+\mathrm{R}_{\text {ф.с. }}+\mathrm{R}_{\mathrm{K} \text { ф.с.-ме.в. }}+\mathrm{R}_{\text {ме.в. }}+\mathrm{R}_{\mathrm{K} \mathrm{ме.в.-} \mathrm{н.заг.}}+\mathrm{R}_{\text {н.заг., }}
\end{gathered}
$$

где

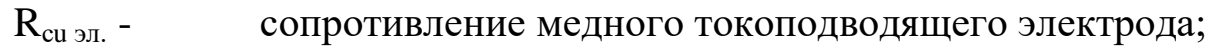

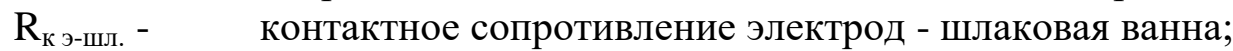

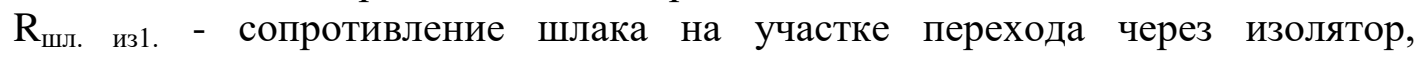

расположенный между токоподводящей и промежуточной секциями;

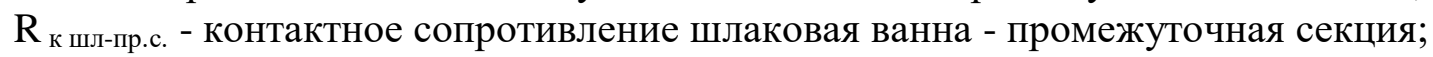

$\mathrm{R}_{\text {пр.с. }} \quad$ сопротивление промежуточной секции;

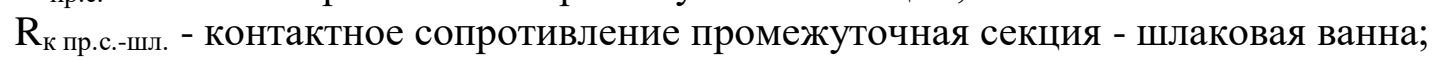

Rшл. из2. - сопротивление шлака на участке перехода через изолятор, расположенный между промежуточной и формирующей секциями; 


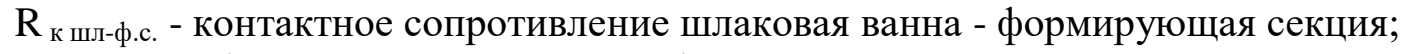

Rф.c. - сопротивление формирующей секции на участке до зеркала металлической ванны;

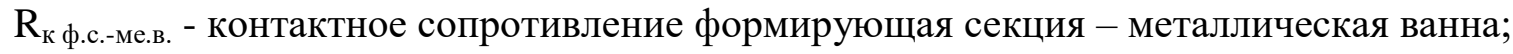

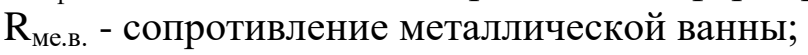

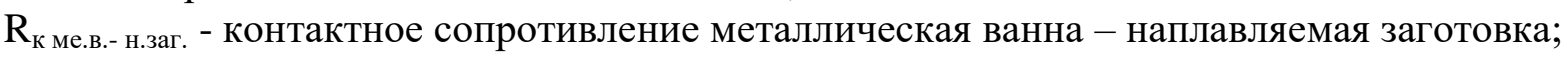

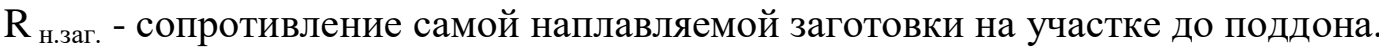

Нетрудно заметить, что цепь Б представлена преимущественно металлическими проводниками, электропроводность которых заметно выше электропроводности шлака, поэтому происходит перераспределение тока и теперь максимальная его плотность приходится на данную цепь, а проплавление происходит у поверхности металлической ванны. Наличие в этой цепи большого количества переходных контактных сопротивлений, о роли которых говорилось в работе [6], приводит к существенному повышению значения электрического сопротивления данной цепи, которое при определенных условиях может превысить сопротивление цепи А.

В проведенных экспериментах снижение толщины наплавляемого слоя привело к снижению величины Rш.з., и в целом к заметному снижению электрического сопротивления цепи А, при этом сопротивление цепи Б осталось практически прежним (снижение величины Rме.в. для сопротивления цепи Б в целом несущественно). Эти изменения в свою очередь, привели к перераспределению тока и соответствующему перемещению участка проплавления вверх от поверхности металлической ванны.

Изменение толщины наплавляемого слоя при наплавке в токоподводящем кристаллизаторе прямоугольного сечения может привести также к тому или иному изменению характера оплавления заготовки по периметру. Поэтому для практического применения при большой толщине наплавляемого слоя может быть рекомендована схема подключения токоподводящей секции, представленная на рис. 4а, что позволит избежать разницы в величине проплавления углов заготовки, а также выровнять эту величину по периметру. При малой толщине наплавляемого слоя целесообразнее снизить плотность тока на участках его подключения к электродам за счет увеличения количества участков подключения (рис. 4б). Эксперименты по наплавке по такой схеме проведенные на холодной модели при величине наплавленного слоя 7 мм показали возможность обеспечить в данном случае более равномерное проплавление, чем в случае использования схемы подключения токоподводящей секции, представленной на рис.2а.

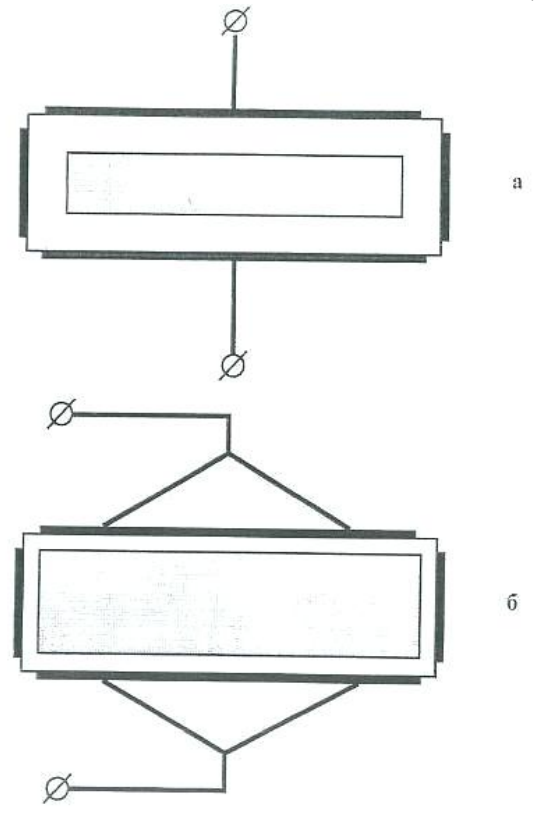

Рис. 4. Схемы электроподключения к электродам 
В результате проведенных исследований установлено, что расположение максимального проплавления заготовки в процессе предварительного нагрева находится у нижнего торца электродов токоподводящей секции, а непосредственно в процессе наплавки - зависит от соотношения толщины наплавляемого слоя и расстояния от токоподводящей секции до уровня металлической ванны. С уменьшением толщины наплавляемого слоя необходимо обеспечить равномерное распределение тока по токоподводящим секциям за счет соответствующих схем их электроподключения.

Несмотря на то, что сделанные выводы получены при использовании неподвижной модели, их можно считать справедливыми и для подвижной модели, имея в виду квазистационарный характер проплавления заготовки.

$$
* * *
$$

1. Кусков Ю.М. Опыт электрошлаковой наплавки плоских заготовок в токоподводящем кристаллизаторе // Автомат. сварка.- 1996.- №7.- С. 54-55.

2. Медовар Б.И., Бойко Г.А., Сердюкова В.П. Физическое моделирование процесса ЭШП расходуемых электродов. // ПроСэм.- 1978.- вып. 9.- С. 38-48.

3. Сущук-Слюсаренко И.И., Лычко И.И., Козулин М.Г., Семенов В.М. Электрошлаковая сварка и наплавка в ремонтных работах / - Киев: Наук. Думка, 1989. - 192с.

4. Цыкуленко К.А., Вислобоков О.М.. Физическое моделирование гидродинамики шлаковой ванны в слябовом токоподводящем кристаллизаторе. (Часть 2. Наплавка). // Современная электрометаллургия.2008.- №3.- C. 18-21.

5. Цыкуленко К.А. Некоторые аспекты формирования наплавленного слоя при порционной электрошлаковой наплавке с применением жидкого присадочного металла. // Современная электрометаллургия.- 2007.- №2.- С. 7-11.

6. Цыкуленко К.А. О роли контактных сопротивлений в процессе электрошлаковой наплавки. // Автомат. сварка.- 2009.- №2.- С. 48-51.

7. Цыкуленко К.А. Физическое моделирование гидродинамики шлаковой ванны в слябовом токоподводящем кристаллизаторе. (Часть 1. Выплавка слитка). // Там же.- 2008.- №1.- С. 3-8.

8. Шевченко В.Ю. Електрошлакова технологія у виробництві сучасних прокатних валків: Автореф. дис. ... канд. техн. наук.- Киев, 2001. - 19 с.

\section{Обухов Д.В., Турабов Р.Ч., Горпинченко А.В., Дюнов В.А., Стрельцов Р.В. Повышение эффективности средств предпускового разогрева двигателя}

Пермский военный институт войск национальной гвардии России (Россия, Пермь)

doi: $10.18411 / \mathrm{sr}-10-02-2018-10$

idsp: 000001:sr-10-02-2018-10

\section{Аннотация}

В работе рассмотрен способ повышения эффективности работы предпускового подогревателя путем установки термоколпака с электронагревателем, работающего от термогенератора (элемент Пельтье) для подогрева дизельного топлива в баке, и нагревательными элементами на топливной магистрали и фильтрах очистки топлива.

Ключевые слова: термогенератор; элемент Пельтье; предпусковой подогреватель; облегчение пуска двигателя.

Зимние условия эксплуатации автомобилей в районах холодного климата, значительно усложняют пуск двигателей. Особенно усложняется пуск двигателей автомобилей при безгаражном хранении. Отрицательная температура наружного воздуха во время стоянки автомобиля с неработающим двигателем вызывает охлаждение смазки до температуры наружного воздуха, увеличение ее вязкости (загустевания), что вызывает необходимость затрачивать большие усилия на проворачивание коленчатого вала двигателя,а также ухудшение распыливания топлива, а, следовательно, и его пусковых качеств. Кроме того, пуск современных двигателей при помощи стартера ухудшается из- 